\title{
Limiting brown rot incidence in peach with tree training and pruning
}

\author{
Claude Bussi ${ }^{1, \star}$, Daniel Plenet ${ }^{2}$, Franck Merlin ${ }^{1}$, Armand Guillermin ${ }^{1}$ and Vincent Mercier ${ }^{1}$ \\ 1 IN.R.A.-U.ER.I., Domaine de Gotheron 2632 St Marcellès Valence France \\ 2 IN.R.A.-P.S.H., Centre de Recherche d'Avignon 8414 Montfavet, France
}

Received 16 January 2015 - Accepted 21 June 2015

\begin{abstract}
Introduction. To limit peach brown rot incidence in a mid-season peach orchard cv. 'Conquise', three combinations of tree training and pruning treatments were assessed: open vase training with conventional pruning (Control); open vase with centrifugal pruning (CentP); vertical axis training with centrifugal pruning (Axis). Materials and methods. The test orchard was divided into four blocks, each with the three tree management treatments in a randomized complete block design. Brown rot incidence as well as fruit production and quality were assessed over five successive years. Results and discussion. The lowest brown rot incidence values were detected under Axis and the highest under Control, with values for CentP being intermediate. The reduced incidences under CentP and Axis training were observed around two weeks before fruit maturity and were maintained until post-harvest storage. Compared to the Control, CentP and Axis resulted in higher trunk cross sectional areas, yields and monetary returns. CentP and Axis also tended to enhance peach internal quality, i.e., increase of total soluble solids, but work time devoted to pruning and thinning under CentP and Axis was greater than for the Control. Conclusion. Appropriate tree management, a vertical axis training system and centrifugal pruning, appears to decrease peach disease sensitivity. This could result in reduced use of pesticide sprays for brown rot control.
\end{abstract}

Keywords: France / Prunus persica / disease sensitivity / Monilinia spp. / tree management / fruit quality

Résumé - Limiter l'incidence des monilioses du pêcher par la forme fruitière et la taille. Introduction. Afin de limiter l'incidence des pourritures de la pêche par monilioses pour la variété Conquise, de maturité de saison, trois combinaisons de forme fruitière et de taille des arbres ont été testées : forme vase ouvert et taille conventionnelle (Control); vase ouvert et taille centrifuge (CentP); forme axe vertical et taille centrifuge (Axe). Matériel et méthodes. Un verger expérimental a été divisé en 4 blocs, chacun avec les 3 traitements sur la conduite de l'arbre. L'incidence des monilioses, ainsi que la production et la qualité des fruits ont été examinées pendant cinq années successives. Résultats et discussion. Les plus faibles incidences de monilioses ont été détectées pour Axe et les plus élevées pour Control, alors que les incidences pour CentP étaient intermédiaires. Les incidences plus faibles de monilioses avec CentP et Axe par rapport à Control, apparaissaient environ deux semaines avant la maturité des fruits et se prolongeaient en conservation post-récolte. Comparativement à Control, CentP et Axe induisirent une augmentation des surfaces de section des troncs, des rendements et des recettes monétaires. CentP et Axe tendirent aussi à améliorer la qualité gustative des fruits par rapport à Control, mais le temps de travail dédié à la taille et à l'éclaircissage était supérieur pour CentP et Axe comparativement à Control. Conclusion. Une forme et une conduite appropriée des arbres, l'axe vertical et la taille centrifuge, sont susceptibles de diminuer la sensibilité de la pêche aux pathogènes. Ce qui pourrait permettre une diminution des applications de pesticides contre les monilioses du pêcher, conformément aux principes de la Protection Intégrée des Vergers.

Mots clés : France / pêcher / Prunus persica / moniliose / Monilinia spp. / sensibilité aux maladies / conduite de l'arbre / qualité du fruit

\section{Introduction}

Peach (Prunus persica L. Batsch) is one of the most important fruits cultivated in the Mediterranean area of Europe

\footnotetext{
^ Corresponding author: claude.bussi@paca.inra.fr
}

(Italy, Spain, France, Greece). Brown rot, mainly caused by Monilinia fructicola (G. Wint.) and Monilinia laxa (Aderh. and Ruhl.) in Europe [1], is the leading stone fruit disease in Southern France [2] where weather conditions conducive to brown rot lead to considerable economic losses [3]. 
Prophylactic measures such as the removal of cankers and mummies from the orchard every winter generally fail to reduce brown rot incidence to a tolerable level. This pathogen is therefore mainly controlled by fungicide spray programs in the field. Alternatives to fungicide spraying, while considered necessary, have not yet been developed. This need is increasingly important because Monilinia has developed resistance to fungicides due to frequent applications during the growing season [4]. Thus, an important challenge for fruit growers concerns the reduced use of pesticides in the peach orchards mandated by Integrated Pest Management rules. More generally, guidelines referring to sustainable farming systems urge users to reduce all inputs (irrigation water, pesticides, etc.) and cropping practices in peach orchards could be adapted to help achieve this aim. Regulated Deficit Irrigation has already been reported to limit the invasion of pathogens such as peach brown rot [5]. Canopy management is another avenue for achieving important gains.

Growers train fruit trees to enhance yield and fruit quality [6]. In peach, the most widely used training system is the open vase, with three to five primary scaffolds that branch to form a vase with an open center [7]. Under this training system, increasing fruit tree density can contribute to increased fruit production with maximum cropping achieved in the Middle Rhone Valley when approximately 550 trees $\mathrm{ha}^{-1}$ were planted [8]. Still, peach production might be improved with higher tree density under other tree training systems, e.g., the optimal peach production with the perpendicular V system occurred with around 1,000-1100 trees ha ${ }^{-1}$ [9]. However, this tree training system results in substantial vegetative growth, in particular excessive annual growth of watersprouts that must be laboriously removed [10]. The Axis system, with a central leader (vertical axis), was reported to be easier to use for training peach trees in high-density orchards (ca. 1,100 trees ha ${ }^{-1}$ ) [11]. The Axis system promotes high yields [12] and contributes to improving light interception by the tree canopy. This latter appears to be crucial for fruit quality and for limiting fruit diseases [13].

Improving light penetration and distribution in the orchard can also depend on the development of pruning procedures that decrease withintree shading [14]. A recent concept of tree pruning - centrifugal pruning - was proposed in apple for this purpose [15]. The aim is to optimize the relationship between vegetative growth and fruiting, especially by encouraging the closeness of leaves and fruit at the periphery of the canopy [16]. Pest incidence notably apple scab, was shown to be reduced in apple orchards where centrifugal pruning was used. It was hypothesized that the microclimate created inside the canopy was less favorable for pest development and especially fungi [17]. When applied to peach trees [18], this innovative pruning method consists of removing current year shoots that limit light penetration inside the canopy much earlier than in conventional summer pruning. The aim is early removal of undesirable watersprouts that congest the center of the canopy, blocking light and leading to a higher humidity around the fruit.

The trend towards a lower incidence of brown rot under centrifugal pruning was observed in an earlier experiment with peach [19]. To confirm and expand this finding, this present study involved the use of centrifugal pruning on peach trees trained to the open vase and the vertical axis systems. Since the adoption of a tree management system depends on its ability to maintain sound agronomic performance, the effects of these practices on tree growth, fruit yield and quality were assessed in addition to labor demand in the orchard and to monetary returns as well, in order to better evaluate its profitability.

\section{Materials and methods}

\subsection{Orchard description}

This study was carried out in a peach orchard planted in 2005 at INRA's Gotheron Experimental Station near Valence in the Middle Rhone Valley, France. The soil was stony alluvial with $15 \%$ clay, $30 \%$ silt and $54 \%$ sand, considered particularly suitable for growing peach trees.

The cultivar used for this study was 'Conquise', a midseason peach (Prunus persica L. Batsch) cultivar on 'GF305' rootstock. Approximate dates of flowering and harvest were March 2 and July 20, respectively. Routine horticultural care in terms of fertilization and soil management was provided. Irrigation scheduling was performed in accordance with RDI (Regulated Deficit Irrigation) rules because RDI was shown to limit brown rot incidence in peach orchards [5]. Hand-thinning was carried out in May to space fruits 10 to $15 \mathrm{~cm}$ along the fruiting shoots to ensure suitable fruit size. Crop phytoprotection was managed according to the Integrated Pest Management system [20]. However, no phytoprotection measures were taken against brown rot in order to observe the effect of tree management on the incidence of this disease. Cankers and mummies were removed from the entire orchard each winter in order to homogenize brown rot inoculum among the different treatments.

\subsection{Experimental design}

The experimental area was comprised of seven rows of trees. The experiments were performed on the three middlerows; the four other tree rows serving as guard rows. Rows were $5 \mathrm{~m}$ apart and distances between trees in the row were $3.80 \mathrm{~m}$ (open vase) and $1.75 \mathrm{~m}$ (axis). Three tree management treatments were carried out: open vase training combined with conventional pruning (Control), open vase training combined with centrifugal pruning (CentP), and axis training with centrifugal pruning (Axis) (figure 1). These management treatments were randomly applied in four blocks with five trees in each experimental unit, with a total of $20(4 \times 5)$ trees per treatment. In order to test the effects of native monilinia inoculum in each experimental unit, it was necessary to limit exogenous contamination by setting up tree barriers. Therefore, all of the guard trees were defruited early each year (in May) to prevent the experimental trees from being contaminated by brown rot. The three central trees of each experimental unit were used for sampling. 


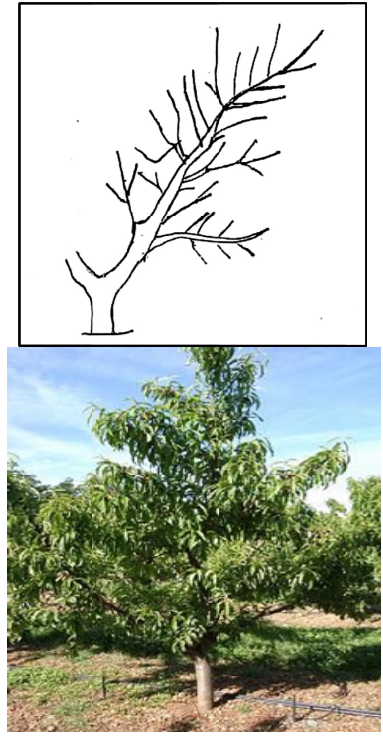

Control

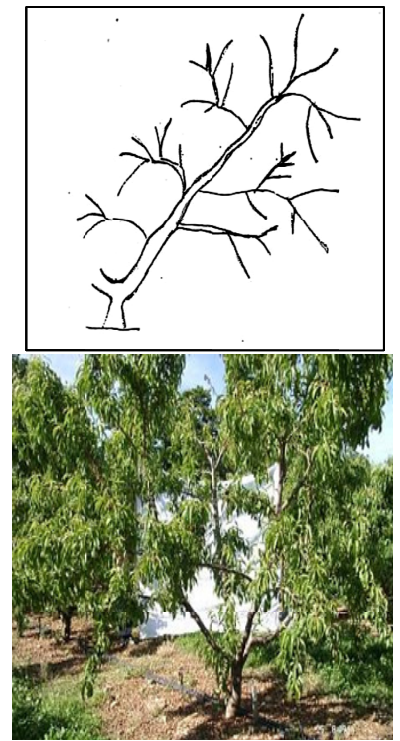

CentP

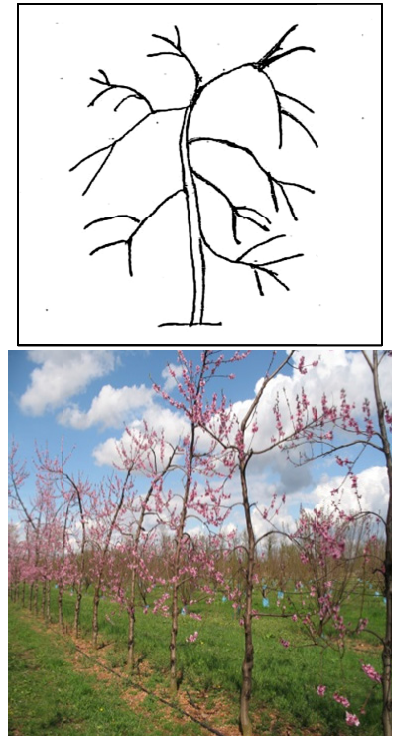

Axis

Figure 1. Training systems and pruning methods in the peach cultivar 'Conquise'. Control $=$ open vase and conventional pruning; CentP = open vase and centrifugal pruning; Axis = vertical axis and centrifugal pruning.

\subsection{Tree management treatments}

In the open vase training system, the central leader is cut back to the first vigorous limb in order to stimulate wide angles on lower branches selected as scaffolds, whereas in the vertical axis system the trees are trained and maintained in a narrow pyramidal shape with a dominant central leader [6]. The Control tree management treatment in our study consisted of an open vase training system combined with a dormant (beginning of March) and a summer (mid-July) pruning [21]. This corresponds to the method usually performed by the fruit growers in the area, leading to considerable leaf density and shade inside the canopy [22]. In the two other tree management treatments, open vase and axis training systems were combined with centrifugal pruning as already described [19].

\subsection{Brown rot incidence}

In 2010, brown rot incidence was evaluated at harvest on all of the fruits of the three central trees in each experimental unit. In 2011, the fruits of the same trees were observed twice a week from around three weeks before fruit maturity to a day before harvest. The aim was to evaluate the percentage of fruits infected by brown rot at each observation date. Infected fruits were removed to prevent the other fruits on the shoot from being contaminated. As a result, brown rot incidence was assessed six times before fruit harvest [2]. From 2010 to 2012 , the post-harvest brown rot incidence was evaluated on 30 selected fruits (uniform diameter and without epidermis defects) sampled at harvest maturity in each experimental unit at the first picking date. Fruits were carefully arranged in fruit crates equipped with special packaging material to prevent any damage. The fruits were transported from the orchard to a growth chamber and stored under controlled conditions (temperature $20{ }^{\circ} \mathrm{C}$; relative humidity $70 \%$ ) for eight days. The infected fruits were removed every day to prevent the other fruit from being contaminated.

\subsection{Fruit production and quality}

Fruit yield was determined at harvest for the trees of each experimental unit, with the exception of the central tree that was used for other purposes (see below). The harvest was completed in three pickings and the fruit were selected in the orchard to differentiate them according to market standards used by industry. Fruit diameters and average fruit weights were evaluated on the basis of a representative sample of the fruit production (about $20 \%$ of the total harvest, as already defined [21]). At harvest, the fruits of the central trees were graded. Total soluble solids (TSS) concentration of each peach was measured for each fruit grade [8]. Relative euros/ha returns were calculated on the basis of tree yield and fruit size distribution of the central sampled tree. Fruit sale prices were provided by the Lorifruit Cooperative where area fruit grower delivered their produce.

Work time for training trees was evaluated from 2008 to 2012. Work time devoted to thinning was also taken into account under the three treatments. Labor demand was expressed for non-control treatments as a percentage of the result of the control treatment. Tree growth was partly evaluated every year in winter by measuring the trunk circumference of all the trees at $0.30 \mathrm{~m}$ from the ground in order to evaluate trunk cross sectional area (TCSA) expressed in $\mathrm{m}^{2} \mathrm{ha}^{-1}$.

\subsection{Statistical analysis}

A classical analysis of variance was used including arcsine square root transformation of the data when needed (brown rot 


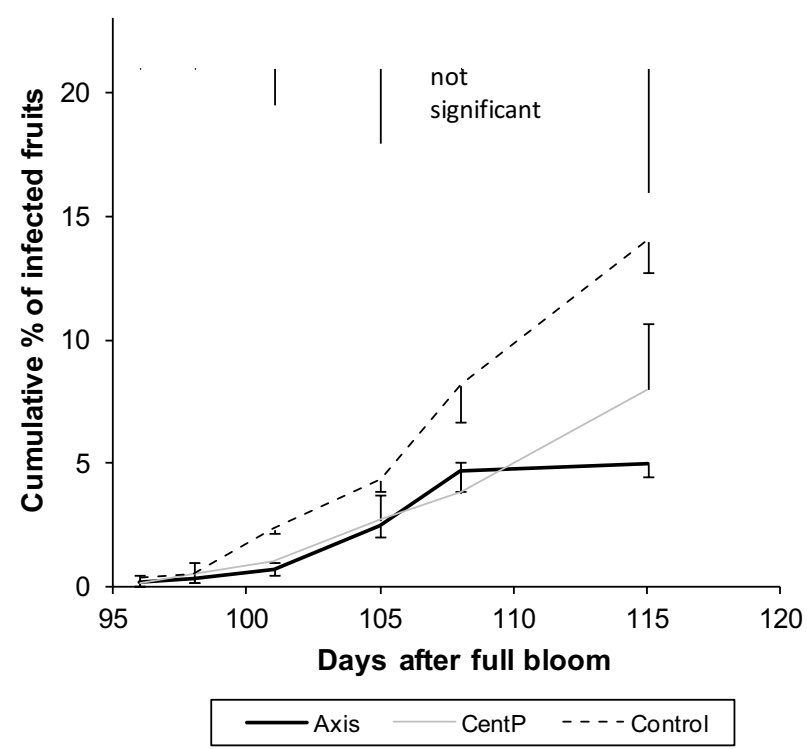

Figure 2. Time-course of brown rot incidence on peach before harvest in 2011 related to tree training and pruning treatments. Brown rot incidence was assessed from around three weeks before fruit maturity until one day before harvest. Standard errors were indicated at each date of measurement and for each treatment. Vertical bars denote Newman-Keuls' maximum confidence intervals for the different treatments at $P=0.05$.

incidence). The Least Square Difference (LSD) was performed for average discrimination (Statgraphics ${ }^{\circledR}$ Plus software). Fruit grade partitioning was compared for the different treatments using a chi-square test [23].

\section{Results and discussion}

\subsection{Brown rot incidence}

Brown rot incidence before harvest was assessed in 2011 on the sampled trees and varied according to treatment ( $f$ igure 2). The lowest brown rot incidence occurred under the centrifugal pruning treatments (CentP and Axis) with significant differences detected around 15-10 days before harvest and close to fruit maturity. At the last date of measurement, brown rot incidence under Axis and CentP represented around one third and one-half that of the Control, respectively. The cumulative percentage of brown rot incidence the day before harvest reached 15\%, 8\% and 5\% in 2011 for Control, CentP and Axis, respectively (figure 2). After eight days of post-harvest storage conditions, the highest incidence of brown rot occurred in 2010, 2011 and 2012 for the Control (ca. 50\%, 25\% and 90\%) and the lowest for the Axis (ca. 30\%, 9\% and 55\%) (figure 3). The differences between these two treatments were significant three times during the eight storage days for each year. Brown rot incidence under CentP was intermediate between these treatments at each measurement date (figure 3).

From 2010 to 2012, the ranking of the three treatments in terms of post-harvest brown rot incidence was identical to those at pre-harvest and at harvest, thus confirming that vertical axis and centrifugal pruning each contributed to reducing
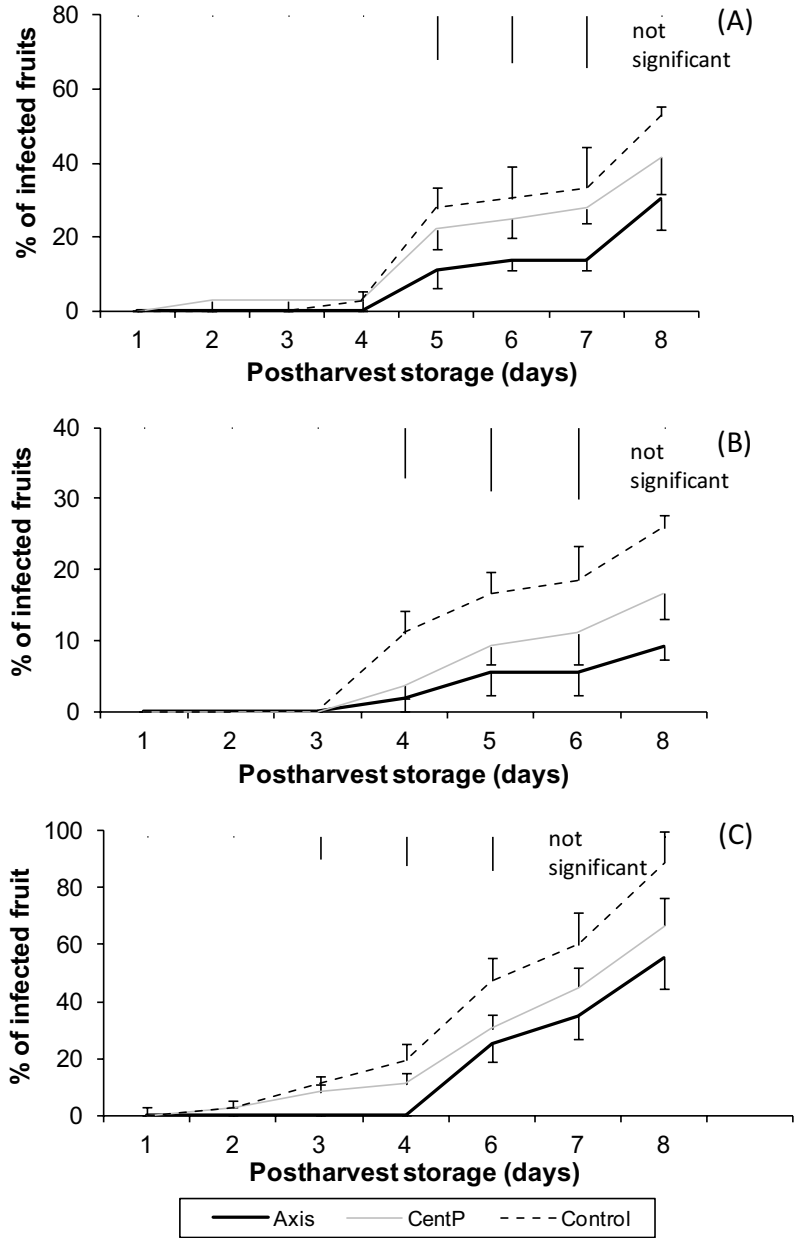

Figure 3. Time-course of brown rot incidence in post-harvest storage conditions in 2010 (A), 2011 (B), 2012 (C) for three tree training and pruning treatments. Standard errors were indicated at each date of measurement and for each treatment. Vertical bars denote NewmanKeuls' maximum confidence intervals for the different treatments at $P=0.05$.

peach sensitivity to brown rot incidence compared to the open vase training system and conventional pruning, respectively. These results suggested that the tree training system and the pruning method each contribute to decreasing peach sensitivity to brown rot, and an accumulation of these effects may occur when practices are combined. Scab was shown to be reduced in apple under severe pruning compared to unpruned trees [24] and this effect was attributed to the difference in the moisture content of air in the plant canopy. Under our conditions, a similar hypothesis can be proposed to explain the trend toward less brown rot incidence with vertical axis than with open vase, and with centrifugal pruning compared to conventional pruning. According to this hypothesis, the innovative training and pruning methods would adversely affect the germination and sporulation of the fungus by inducing more aeration and less humidity around the peach. This would take effect as soon as centrifugal pruning is carried out in the spring, probably explaining the appearance of brown rot limitation under CentP and Axis around two weeks before fruit harvest maturity. 
Table I. Average productivity, labour demand, monetary returns and vegetative growth of peach trees cv. 'Conquise' from 2008 to 2012 in relation to training and pruning treatments.

\begin{tabular}{ccccccc}
\hline Treatment & $\begin{array}{c}\text { Flower } \\
\text { number per m } \\
\text { shoot length }\end{array}$ & $\begin{array}{c}\text { Yield } \\
\left(\mathrm{t} \mathrm{ha}^{-1}\right)\end{array}$ & $\begin{array}{c}\text { Average } \\
\text { fruit weight } \\
(\mathrm{g})\end{array}$ & $\begin{array}{c}\text { Labour } \\
\text { demand } \\
(\% \text { of Control })\end{array}$ & $\begin{array}{c}\text { Monetary } \\
\text { returns } \\
\left(€ \mathrm{ha}^{-1}\right)\end{array}$ & $\begin{array}{c}\text { Trunk cross } \\
\text { sectional area } \\
\left(\mathrm{m}^{2} \mathrm{ha}^{-1}\right)\end{array}$ \\
\hline Control & $35 \mathrm{~b}$ & $16.1 \mathrm{~b}$ & 143 & $100 \mathrm{~b}$ & $8,230 \mathrm{c}$ & $9.3 \mathrm{c}$ \\
CentP & $46 \mathrm{a}$ & $20.6 \mathrm{a}$ & 143 & $119 \mathrm{ab}$ & $9,286 \mathrm{~b}$ & $10.3 \mathrm{~b}$ \\
Axis & $40 \mathrm{ab}$ & $22.2 \mathrm{a}$ & 147 & $138 \mathrm{a}$ & $10,902 \mathrm{a}$ & $115 \mathrm{a}$ \\
\hline
\end{tabular}

Values within columns followed by different letters are significantly different at $P=0.05$.

Table II. Average peach grade partitioning (\%) and total soluble solids (TSS) per fruit grade of peach trees cv. 'Conquise' from 2008 to 2012 in relation to training and pruning treatments. Marketable grades correspond to fruit diameters: B, 61-67 mm; A, 67-73 mm; AA, 73-80 mm.

\begin{tabular}{|c|c|c|c|c|c|c|c|}
\hline \multirow{2}{*}{ Treatments } & \multicolumn{2}{|c|}{ Grade AA } & \multicolumn{2}{|c|}{ Grade A } & \multicolumn{2}{|c|}{ Grade B } & All grades \\
\hline & $\%$ & TSS & $\%$ & TSS & $\%$ & TSS & TSS \\
\hline Control & 31.2 & $12.0 \mathrm{~b}$ & 50.6 & 10.9 & 16.9 & 9.5 & 10.9 \\
\hline CentP & 34.0 & 12.3 & 41.8 & 10.9 & 23.8 & $10.3 \mathrm{a}$ & 11.3 \\
\hline Axis & 39.9 & $13.3 \mathrm{a}$ & 43.2 & 11.8 & 16.3 & $10.4 \mathrm{a}$ & 11.8 \\
\hline
\end{tabular}

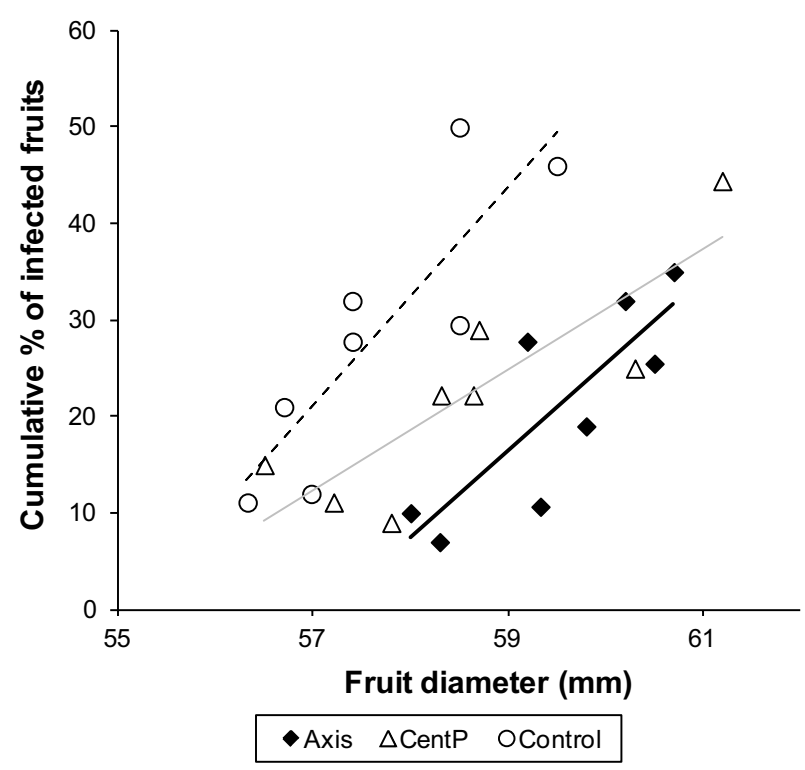

Figure 4. Peach diameters related to the percentage of fruit infected by brown rot at harvest. Correlation coefficients were significant at $P=0.05\left(r^{2}=0.74,0.72,0.68\right.$ for Control, CentP and Axis, respectively).

The relationship between fruit growth and brown rot incidence was analyzed in 2010 by plotting fruit diameter against the incidence of brown rot at harvest (figure 4). Fruit growth and brown rot incidence were not significantly related for the three clustered treatments $(P>0.05)$. However, these two variables were linearly related within each of the three treatments $(P<0.05)$ (figure 4$)$. The regression curves were represented for each treatment:

Control: $y=11.4 x-626.6\left(r^{2}=0.74\right)$

CentP: $y=6.2 x-33.4\left(r^{2}=0.72\right)$

Axis: $y=9.0 x-513.7\left(r^{2}=0.68\right)$.

Reduced fruit infection related to a direct limitation of fruit growth within each treatment was in accordance with the finding that fruit epidermis micro-cracking is particularly limited by low fruit growth, thus reducing pathogen invasion [25, 26]. Nevertheless, because no significant differences in average peach weight were revealed under the three treatments, variations of epidermis micro-cracking cannot be assumed to be responsible for the discrepancies of brown rot incidence between the three training and pruning treatments. Further studies will be necessary, especially on microclimate parameters within the canopy, to better understand how peach tree management practices affect brown rot incidence.

\subsection{Fruit production and quality}

On average, from 2008 to 2012, CentP and Axis induced $+31 \%$ and $+15 \%$ higher flower number per $m$ shoot length compared to the Control (table I). For the same period, trees under CentP and Axis had significantly higher yields than the Control, $+28 \%$ and $+38 \%$ respectively (table I). Despite the discrepancy in yield between the treatments, the average fruit weight only slightly differed: $+2 \%$ under Axis compared to the other treatments (table I). As a result, fruit grade partitioning did not significantly differ between the three treatments (table II). Fruit TSS generally appeared to be higher for the high fruit size (grade AA) than for the low one (grade B), and they only varied slightly under the treatments. On average, TSS tended to be higher under CentP and Axis $(+2 \%$ and $+8 \%$, respectively) (table II). The lowest and the highest peach sizes exhibited significantly higher TSS under CentP and Axis than under Control (table II).

The ranking of the three treatments in terms of peach tree growth, productivity and TSS levels could be assumed to be the result of maximizing the amount of light interception and optimizing the light distribution within the canopy [7]. With regard to tree training, vertical axis has been shown to provide optimum light interception inside the canopy compared to the conventional open vase [29]. With respect to tree pruning, water-sprout removal early in spring performed under CentP possibly enhanced light penetration within the tree canopy 
compared to Control [15]. Moreover, it was reported that the proximity of fruit to assimilate source on peach shoots, favored by CentP could enhance carbohydrate supply to the fruit [28]. The trend towards higher total soluble solids under CentP and Axis with respect to ConvP showed that these methods were likely to improve peach quality for a mid-season cultivar.

\subsection{Work time and monetary returns}

From 2008 to 2012, work time devoted to pruning and thinning under CentP and Axis was $19 \%$ and $38 \%$ higher than that for the Control, respectively (table I). On average from 2008 to 2012, relative monetary returns tended to be higher for CentP $(+13 \%)$ and were significantly higher for Axis $(+32 \%)$ ( $t a-$ ble I). Concerning tree vigor, the trunk cross sectional area (TCSA) in 2012 was significantly higher under Axis than under CentP $(+12 \%)$ and Control $(+23 \%)$ (table I). Because harvested peach grade partitioning was only slightly affected and yield was largely enhanced, monetary returns tended to be higher under CentP and Axis than under ConvP for the five years of this experiment. Work time increased under CentP and Axis compared to ConvP in a proportion similar to that of monetary returns, suggesting that the supplemental costs for managing centrifugal pruning and vertical axis training tended to be economically compensated for by higher fruit production than under conventional methods.

\section{Conclusion}

Brown rot incidence was reduced by vertical axis training and centrifugal pruning compared to conventional practice. Moreover, while no fungicides were applied against brown rot in our conditions, it might be assumed that the increased openness of the canopy, in addition to the preferential location of the fruit at the periphery of the tree under CentP compared to that under conventional pruning, is likely to improve the efficiency of spraying [31]. This assumption, which remains to be tested, combined with the limited incidence of brown rot under the Axis and CentP management practices, might help fruit growers reduce the use of pesticides in peach orchards. That is, help them comply with Integrated Pest Management rules and towards an environmentally respectful and quality-based fruit production system. Moreover, these methods appeared likely to improve peach quality and fruit yield, possibly increasing their market value. Nevertheless production costs should be further investigated to draw more accurate conclusions about the economic conditions of production under vertical axis and centrifugal pruning. Experiments should be assessed for the entire life of the orchard in order to eventually transmit these methods to fruit growers.

Acknowledgements. The authors are indebted to the French Ministry of Ecology and Sustainable Development for its financial support within the framework of the program, 'Evaluation and risks linked to pesticide use', and to D. Chauffour and H. Chenevotot for their technical assistance.

\section{References}

[1] Mari M., Gregori R., Donati I., post-harvest control of Monilinia laxa and Rhizopus stolonifer in stone fruit by paracetic acid, Post-harvest Biol. Technol. 33 (2004) 319-325.

[2] Mercier V., Frachon S., Demoulin G., Monilioses: période de sensibilité des pêches au verger, Phytoma - La Défense des Végétaux 558 (2003) 38-40.

[3] Barkai-Golan R., post-harvest disease of fruit and vegetables, In: Development and control, Elsevier, Amsterdam 2001, pp. 150-173.

[4] Holb I.J., Schnabel G., Differential effect of triazoles on mycelial growth and disease measurements of Monilinia fructicola isolates with reduced sensitivity to DMI fungicides, Crop Prot. 26 (2007) 753-759.

[5] Mercier V., Bussi C., Lescourret F., Genard M., Effects of different irrigation regimes applied during the final stage of rapid growth on an early maturing peach cultivar, Irrig. Sci. 27 (2009) 297-306.

[6] Jackson D., Looney N., Palmer J., Pruning and training of deciduous fruit trees, In: Jackson D., Looney N., Marley-Bunker M. (Eds.), ${ }^{\text {rd }}$ Ed., Temperate and subtropical fruit production Wellingford, UK 2010, pp. 44-61.

[7] Grossman Y.L., DeJong T.M., Training and pruning system effects on vegetative growth potential, light interception and cropping efficiency in peach, J. Amer. Soc. Hort. Sci. 123 (1998) 158-1064.

[8] Bussi C., Huguet J.G., Besset J., Girard T., The consequences of cultural practices on growth and cropping of peach subjected to localized irrigation: effects of soil management, nitrogen fertilization and tree density, J. Hort. Sci. 69 (1994) 905-914.

[9] DeJong T.M., Day J.F., Doyle J.F., Johnson R.S., The Kearney Agricultural Center Perpendicular "V" (KAC-V) orchard system for peaches and nectarines, HortTechnol. 4 (1994) 362-367.

[10] Bussi C., Bruchou C., Lescourret F., Response of watersprout growth to fruit load and intensity of dormant pruning in peach tree, Sci. Hort 13 (2011) 725-731.

[11] Bassi D., Dima A., Scorza R., Tree structure and pruning response of six peach growth forms, J. Amer. Soc. Hort Sci. 119 (1994) 378-382.

[12] Nunez R., Iglesias I., Montserrat R., Alegre S., Eficiencia agronomica de seis sistemas de formacion con la variedad de melocoton 'Merrill O'Henry' (Prunus persica (Batsch)), ITEA 12 (2006) 13-26.

[13] Cooley D.R., Autio W.R., Summer pruning of apple: impacts on disease management, Adv. Hort. Sci. 25 (211) 199-204.

[14] Genard M., Baret F., Spatial and temporal variation of light inside peach trees, J. Amer. Soc. Hort. Sci. 119 (1994) 669-677.

[15] Willaume M., Lauri P.E., Sinoquet H., Light interception in apple trees influenced by canopy architecture manipulation, Trees 18 (2004) 705-713.

[16] Lauri P.E., Willaume M., Larrive G., Lespinasse J.M., The concept of centrifugal training in apple aimed at optimizing the relationship between growth and fruiting, Acta Hort. 636 (2004) 35-42.

[17] Simon S., Lauri P.E., Brun L., Defrance H., Sauphanor, B., Does manipulation of fruittree architecture affect the development of pests and pathogens? A case study in an organic apple orchard, J. Hort. Sci. Biot. 81 (2006) 765-773. 
[18] Plenet D., Navarro E., De Bruyne F., Guinet P., Blanc P., Mercier V., Bussi C, Lescourret F., OptiPeach, a prototype of cropping system for Integrated Fruit Production in peach (Prunus persica L.) orchards, In: Wery et al. (Eds.), Proceeding of Agro210 the $\mathrm{XI}^{\text {th }}$, European Society of Agronomy Congress, Agropolis International Editions, Montpellier, France (2010) 823-824.

[19] Bussi C., Plenet D., Effects of centrifugal pruning on agronomic performance and fruit quality in a mediummaturing peach cultivar, Eur. J. Hort. Sci. 77 (2012) 129-136.

[20] ACTA, Contrôles périodiques en verger de pêcher, ACTA lutte intégrée éditions, Paris, France (1979).

[21] Marini R.P., Vegetative growth yield and fruit quality of peach as influenced by dormant pruning summer pruning and summer topping, J. Am. Soc. Hort. Sci. 110 (1985) 133-139.

[22] Li S.H., Zhang X.P., Meng Z.Q., Wang X., Response of peach trees to modified pruning, 1- Vegetative growth, N.Z.J. Crop Hort. Sci. 22 (1994) 401-417.

[23] Scherrer B., Biostatistique, Gaëtan Morin Ed., Chicoutimi, Canada (1984).

[24] Holb I.J., Effects of pruning on apple scab in organic apple production, Plant Dis. 89 (2005) 611-618.

[25] Gibert C., Chadoeuf J., Vercambre G., Genard M., Lescourret F., Cuticular cracking on nectarine fruit surface. Spatial distribution and development in relation to irrigation and thinning, J. Am. Soc. Hort. Sci. 132 (2007) 583-591.

[26] Mercier V., Bussi C., Plenet D., Lescourret F., Effects of limiting irrigation and of manual pruning on brown rot incidence in peach, Crop Prot. 27 (2008) 678-688.

[27] Houma A.R., Cherif M., Boubaker A., Effect of nitrogen fertilizing green pruning and fungicide treatments on Botrytis bunch rot of grapes, J. Plant Pathol. 8 (1998) 115-124.

[28] Corelli-Grappadelli L., Coston D.C., Thinning pattern and light environment in peach tree canopies influence fruit quality, HortScience 26 (1991) 1464-1466.

[29] Jajo A., Rahim M.A., Serra S., Gagliardi F., Jajo N.K., Musacchi S., Costa G., Bonghi C., Trainotti L., Impact of tree training system, branch type and position in the canopy on the ripening homogeneity of 'Abbé Fétel' pear fruit, Tree Genet. Genome 1 (2014) 1477-1488.

[30] Gelly M., Recasens I., Girona J., Mata M., Arbones A., Rufat J., Marsal J., Effects of stage II and post-harvest deficit irrigation on peach quality during maturation and after cold storage, J. Sci. Food Agric. 84 (2004) 561-568.

[31] Cross J.V., Walklate P.J., Murray R.A., Richardson G.M., Spray deposits and losses in different sized apple trees from an axial fan orchard sprayer: 3 . Effects of air volumetric flow rate, Crop Prot. 22 (203) 381-394.

Cite this article as: Claude Bussi, Daniel Plenet, Franck Merlin, Armand Guillermin, Vincent Mercier. Limiting brown rot incidence in peach with tree training and pruning. Fruits 70 (2015) 303-309. 